International Journal of Current Advanced Research

ISSN: O: 2319-6475, ISSN: P: 2319 - 6505, Impact Factor: SJIF: 5.995

Available Online at www.journalijcar.org

Volume 6; Issue 4; April 2017; Page No. 3147-3149

DOI: http://dx.doi.org/10.24327/ijcar.2017.3149.0206

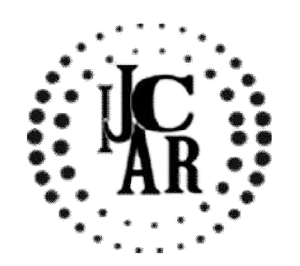

Research Article

\title{
KNOWLEDGE AND AWARENESS ON DIETARY PRACTICE INFLUENCING ORAL HYGIENE AMONG ADULTS IN RURAL AREAS OF THIRUVALLUR DISTRICT
}

\author{
Dhanalakshmi.S*1., Dhanraj ${ }^{2}$ and Ashok $^{3}$
}

Saveetha Dental College, Chennai-600077, Tamilnadu, India

\begin{tabular}{|c|c|}
\hline 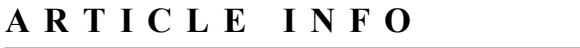 & A B S T R A C T \\
\hline Article History: & AIM: To do a survey on knowledge and awareness on dietary practice influencing oral \\
\hline $\begin{array}{l}\text { Received } 10^{\text {th }} \text { January, } 2017 \\
\text { Received in revised form } 19^{\text {th }} \text { February, } 2017 \\
\text { Accepted } 16^{\text {th }} \text { March, } 2017 \\
\text { Published online } 28^{\text {th }} \text { April, } 2017\end{array}$ & $\begin{array}{l}\text { hygiene among adults in rural areas of thiruvallur district. } \\
\text { Objective: Dental health is not alone concerned with brushing and flossing but also } \\
\text { includes dietary habits of people. The physical characteristics of o food, particularly how } \\
\text { much it clings to the teeth also influence the tooth decay equation. Methods: A survey was } \\
\text { conducted for } 100 \text { people in kaivandur, Pandur, Siruvanur of Thrivallur district. }\end{array}$ \\
\hline Key words: & $\begin{array}{l}\text { A questionnaire about thier dietary practice was given to them which was tilled and was } \\
\text { returned. Results: About } 80 \% \text { of the participants drink coffee and tea twice a day. } 50 \% \text { of }\end{array}$ \\
\hline Hygiene Among Adults In Rural Areas & $\begin{array}{l}\text { the participants drink soda drinks and citrus juices twice a month.most of them takein fast } \\
\text { food once in a month. } 70 \% \text { of the people don't visit there dentist regularly. Conclusion: } \\
\text { The people had knowledge about the effect of chocolates and ice cream on the teeth. } \\
\text { They did not have awareness about the effect coffee, tea and citrus juices. So the study was } \\
\text { carried to enable the public about the effect of these products and to create awareness } \\
\text { among them. Hence Dental health programs should be enabled to have knowledge about } \\
\text { oral hygiene. }\end{array}$ \\
\hline
\end{tabular}

Copyright $₫ 2017$ Dhanalakshmi.S., Dhanraj and Ashok. This is an open access article distributed under the Creative Commons Attribution

License, which permits unrestricted use, distribution, and reproduction in any medium, provided the original work is properly cited.

\section{INTRODUCTION}

Oral health is significantly related to oral health behaviours and their knowledge. Oral health knowledge contributes to good oral health, but unless attitudes and habits are developed and put into practice. It is important to review the knowledge, attitude, and practices of the health of adults, even though they are educated, with the objectives of inculcating healthy lifestyles practices to last for a lifetime ${ }^{(1)}$.

For many years the message to prevent oral diseases was "not to eat sugar and sugary foods". Not only sugar but many other products are also harm to our teeth. We consume many things which has a very bad effect on our teeth.This survey was carried to create a awareness on oral hygiene to the people in rural area. ${ }^{(3)}$ Preventive dental knowledge is the precursor of the reduction of caries prevalence. ${ }^{8}$ It was noticed that young children's oral health conditions were influenced by their parents' knowledge of dental preventive measures. These included good oral hygiene, healthy and balanced diet and periodic dental clinic visits. $^{(2)}$

\section{MATERIALS AND METHODOLOGY}

A cross sectional pilot study was conducted in three villages of Thrivallurdistrict.

*Corresponding author: Dhanalakshmi.S

Saveetha Dental College, Chennai-600077, Tamilnadu, India
The villages were Pandur, kaivandur and Siruvanur. A total of 100 people among the age group 24-55 participated among which $68 \%$ were females and $32 \%$ were males. The questionnaire was given to theparticipants which was filled and returned.

Questionnaire content:(1) information about participants name, age and sex (2) diet habits like intake of coffee, tea, sports drinks, soda drinks, citrus juices and alcohol and their respective frequencies were recorded.(3) consumption of chocolates, ice creams, fast food and their frequencies were recorded. (4) oral hygiene practices like visiting the dentist, flossing of mouth after meal or after eating chocolates was questioned.(5) The participants awareness about the effect of coffee, tea, soda drinks, citrus juices, chocolates and ice creams on their teeth was examined.

The result of the study was analysed statistically.

\section{RESULTS AND DISCUSSION}

The result of the study was $55 \%$ of them had coffee or tea twice a day. $23 \%$ of them drink sports drinks. $74 \%$ of them eat ice cream once a month. $54 \%$ of them consume chocolates once a month. $38 \%$ of them consume alcohol. $56 \%$ of them drink citrus juices like lemon and orange juices. $38 \%$ of them drink soda drinks and only $51 \%$ of them visit their dentist regularly. The people had awareness about the effect of ice creams and chocolates. They did not have knowledge on the 
effect of coffee, tea, citrus juices and soda drinks. Oral hygiene does not end with bushing and flossing. Dietary practice also influences oral hygiene.so Dental health programs use be conducted in these places to create awareness about the effect of consumption of these products. It should be appreciated that the most recent large-scale randomized clinical trials have reached inconsistent conclusions regarding antioxidants and their potential for preventing cancer. Nonetheless, foods that might be recommended to atrisk patients (eg, smokers, alcohol users) because they have substantial antioxidant properties include the following:

- Beta-carotene - Potatoes, carrots, cantaloupe, squash, apricots, pumpkin, mangos, and some green leafy vegetables (collard greens, spinach, kale)

- Vitamin A - Liver, sweet potatoes, carrots, milk, egg yolks, and mozzarella cheese

- Vitamin C - Fruit, vegetables, cereals, beef, poultry, and fish

- Selenium (a mineral) - Rice, wheat, meats, bread, Brazil nuts

Coffee may also include antioxidants. ${ }^{(4)}$

In a study assessing the antioxidant enzymatic activity in saliva among patients with oral cancer and odontogenic cysts compared with healthy controls, subjects with oral cancer were found to exhibit lower total antioxidant capacity and salivary peroxidase and superoxide dismutase activity in their saliva than controls. The evidence was also interpreted as suggesting that the lower antioxidants levels in saliva among subjects with odontogenic cysts could indicate a role of antioxidants in the development of tumors (neoplastic transformation) that form within these structures. Many years of research have established that dietary factors are directly related to dental caries and erosion. ${ }^{(7)}$ Significant risk factors for these abnormalities include fat and sugar intake in both children and adults.In fact, not only does childhood sugar intake contribute to the development of caries, but the development of pediatric caries in children aged 5 years and younger is significantly associated with maternal weight and intake of sugar and fat by expectant mothers during pregnancy. Dietary habits and the risk of caries in children may also be confounded by maternal educational level. ${ }^{(5)}$

Caries also occurs in adults, and its incidence appears to increase with age. In fact, incidence rates are similar to those observed in children. Numerous studies in Europe (Ireland, Netherlands, United Kingdom, France) and in the United states suggest that the dietary factors in children may be as important as they are in adults. In a recent study, severe tooth loss in older adults was found to be a key indicator of a compromised dietary quality. Evidence also shows that sport drinks may be increasing the incidence of dental erosion, which can precede caries in both child and adult athletes. ${ }^{(6)}$

\begin{tabular}{cccc}
\hline S.No & Food items & Yes & No \\
\hline 1 & Coffee and tea & $85 \%$ & $25 \%$ \\
2 & Sports drinks & $23 \%$ & $77 \%$ \\
3 & Ice creams & $89 \%$ & $11 \%$ \\
4 & Chocolates & $85 \%$ & $25 \%$ \\
5 & Soda drinks & $73 \%$ & $27 \%$ \\
6 & Alcohol & $38 \%$ & $62 \%$ \\
7 & Citrus juices & $56 \%$ & $44 \%$ \\
8 & Fast food & $47 \%$ & $53 \%$ \\
\hline
\end{tabular}

\section{Frequency of consuming ice creams}

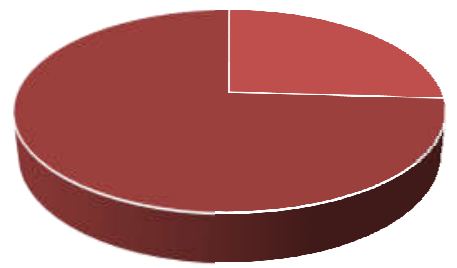

" Daily - Once a week - Once a month

\section{Frequency of drinking coffee and tea}

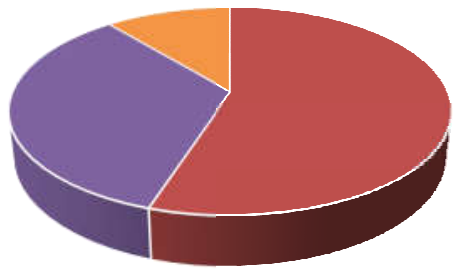

- Once a day $\quad$ Twice a day $\quad$ More than twice a day

Frequency of consuming chocolates

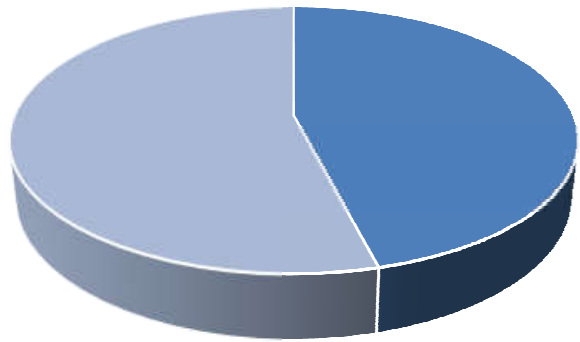

- Daily " Once a week = Once a month

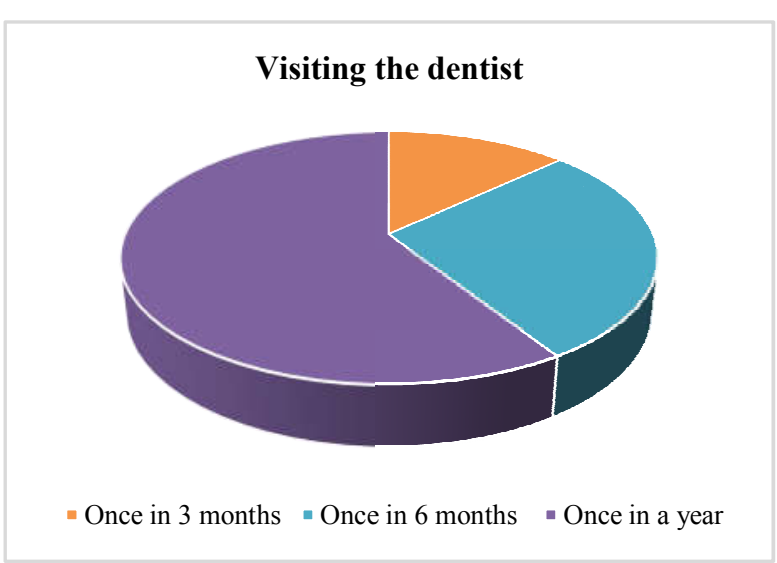

\section{CONCLUSION}

Oral hygiene behavior exhibited by the university students sample was similar. Majority cleaned their teeth, although only once. Smoking habit was not exhibited by the vast majority of students. Frequent smokers perceived oral health problems more than other students. Current oral hygiene measures, appropriately used and in conjunction with regular 
professional care, are capable of virtually preventing caries and periodontal disease and maintaining oral health. Tooth brushing and flossing are most commonly used oral hygiene aids, though interdental brushes and wooden sticks can offer advantages in periodontally involved dentitions. Patient's adherence to the periodontal treatment is fundamental to the success of the therapy. Lack of response to the clinician's instructions is influenced by various factors, including gender, age, and psychosocial profile.

\section{Reference}

1. McGrath C, Sham AS, Ho DK, Wong JH. The impact of dental neglect on oral health: A population based study in Hong Kong. Int Dent J. 2007; 57:3-8. [PubMed]

2. Nagesh H. Oral Health related knowledge, attitude and practice [KAP] among 16-18 yr old students of 4 preuniversity colleges in Bangalore south India. RGUHS J Dent Sci. 2008;2:12-8
3. Ostberg AL, Jarkman $\mathrm{K}$, Lindblad U, Halling A. Adolescents' perceptions of oral health and influencing factors: A qualitative study. ActaOdontolScand. 2002; 60:167-73. [PubMed]

4. Coolidge T, Heima M, Johnson EK, Weinstein P. The dental neglect scale in adolescents. BMC Oral Health. 2009; 9:2.

5. Carneiro L, Kabulwa M, Makyao M, Mrosso G, Choum R. Oral health knowledge and practices of secondary school students, Tanga, Tanzania. Int J Dent 2011. 2011:806258.

6. Masanja IM, Mumghamba EG. Knowledge on gingivitis and oral hygiene practices among secondary school adolescents in rural and urban Morogoro, Tanzania. Int J Dent Hyg. 2004; 2:172-8.

7. Kahabuka FK, Mbawalla HS. Oral health knowledge and practices among Dar es Salaam institutionalized former street children aged 7-16 years. Int J Dent Hyg. $2006 ; 4: 174-8$

\section{How to cite this article:}

Dhanalakshmi.S., Dhanraj and Ashok (2017) ' Knowledge And Awareness On Dietary Practice Influencing Oral Hygiene Among Adults In Rural Areas Of Thiruvallur District', International Journal of Current Advanced Research, 06(04), pp. 3147-3149.DOI: http://dx.doi.org/10.24327/ijcar.2017.3149.0206 